\title{
Identification of Type \& Location of a Fault in a Distributed Generation System Using Neural Network
}

\author{
Saurabh Awasthi ${ }^{1}$, Ranjay Singh ${ }^{2}$ \\ ${ }^{1,2}$ Dit university, Department of Electrical Engineering, Mussoorie Diversion Road, Dehradun 248001, India
}

\begin{abstract}
Distributed generation system offers several distinguish advantages over conventional centralized generation system. However protection scheme of such system has always been a challenge as it can leads to numerous unwanted situation such as reclosing failure. This paper proposes a Neural Network based method to identify the location and type of a particular fault that may occur in a distribution network operated with Distributed generation system. A distributed network with DG has been considered for data generation and based upon the data so collected in terms of sample of Voltage and current, after simulation, training, testing and validation of Neural Network is carried out. In the event of any fault within the system the trained neural network identify its type and location on account of the pattern recorded earlier.
\end{abstract}

Keywords: Distributed Generation, Renewable Energy systems, Neural Network, Simulation, Distribution Network

\section{Introduction}

Electricity can be generated either by conventional centralized generation system or through distributed generation system [1]. With centralized generation scheme, generation is mainly done at large generation facilities, and then is transferred to the end consumer through the transmission and distribution grids. These generation systems derive major portion of generation from large central-station plants, such as fossil fuel (coal, gas powered), nuclear, large solar power plants or hydropower plants. However because of numerous constraints such as fossil-fuels depletion, heightened environmental concerns, and Increased T\&D Cost concept of large central-station plants is weakening [2].

To minimise these effects the paradigm has been shifted from large central-station to small scale generation units. This new technology is called Distributed generation system.

However despite of several advantages it offered over conventional system such as such as reduction in the T \& D cost, improvement in rural electrification \& energy efficiency, easier installation, higher reliability \& security and very less influence on the environment [3] ,protection is one area which need special attention while dealing with Distribution network as any abnormal condition may lead to disconnection of the healthy components from the system and may further cause obstacles in carrying out protection procedure.[4] Also Introduction of DG may introduce network transients, harmonics and issues related to regulation [5-7].

In this paper, real time system has been considered having two Distributed generators which are interconnected with a utility grid. The system is equivalently modelled in MATLAB Simulink. After modelling of the system, load flow and short circuit is being carried out at different point through different faults. Based upon the data so collected training, validation and testing of an $\mathrm{ANN}$ is done.
The paper is organised as follows. The protection procedure need to be followed is discussed in Section 2. System configuration of the real time system has been modelled in Section 3. Section 4 discusses the Offline calculation. Applications of Neural Network for Data classification have been discussed in Section 5. Online Calculation has been carried out in Section 6. Section 7 shows the Test results and finally Section 8 concludes the paper.

\section{Protection Procedure}

It comprises three main sections: the first stage is the collection of data after modelling of distribution network, offline calculation and next to defines an appropriate actuator. The second stage is to perform online calculation for identification of the fault type and its location followed by the final step of the isolation of the faulty zone for protecting the distribution network [8].

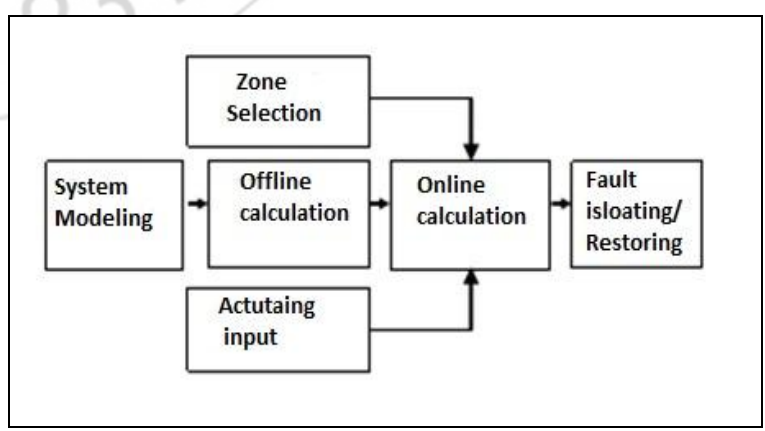

Figure 1: Protection Procedure [8]

\subsection{First step}

It involves load flow analysis for finding normal current contribution through each source in the corresponding network \& neural network training to conduct online fault location [8]. 


\section{International Journal of Science and Research (IJSR) \\ ISSN (Online): 2319-7064}

Index Copernicus Value (2013): 6.14 | Impact Factor (2015): 6.391

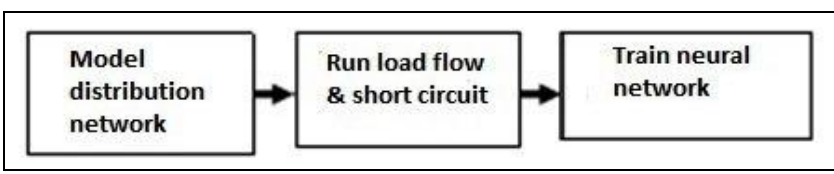

Figure 2 Offline calculation [8]

In a faulty system each fault point is characterized by the current contribution through each source. The data so collected will then be used for training of neural network for finding the mathematical function of distribution network. Thus short circuit analysis shall need to be carrying out for each type of faults which involves different phases in every step points. The next approach is division of the system into zones that can satisfy the necessity of planning and islanding conditions [7].

\subsection{Second Step}

The main objective of the second stage is to sense the fault, followed by identification of type \& location of fault online [8]. Under normal conditions the total current contribution through all sources is equal to the total load. However in case of a fault, fault current will be considerably larger than total load current. For detecting the fault conditions total currents of generator \& loads are required to be compared. The next step is to define fault type and location, and thereby the faulted zone.

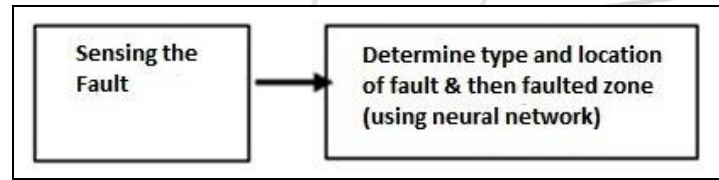

Figure 3: Online calculation [8] for 10 different types of faults is calculated. Normalization has been done using Equation (1). Also for normalization of network inputs the same equation has been used [9]:

$$
I_{\text {normal }}=\frac{2 I-I_{\max }-I_{\min }}{I_{\max }-I_{\min }}
$$

Where $I_{\min }, I_{\max }-$ minimum, maximum fault currents for each type of fault. The complete instruction for fault identification program has been shown in figure 4 .

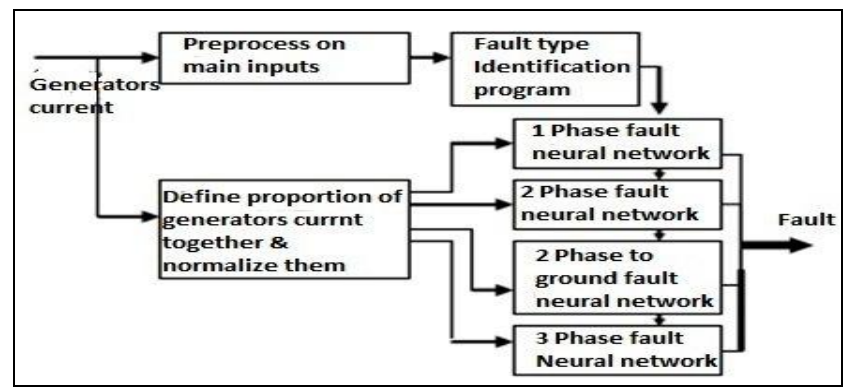

Figure 4: Instruction for Fault identification program [8]

\subsection{Third step}

At the final phase the faulty part needs to be isolated through tripping zone forming breakers. After the identification of the faulty zone by neural network it is desired to cross check with input current direction from the breaker in order to assure opening of the correct faulted zone [7].

\section{System configuration \& modelling}

A real time real time distribution network and the system equivalently model in MATLAB Simulink has been shown in figure 5 .

It can be used to identify fault type as level of pre and postfault current of generators are high. The normalized current

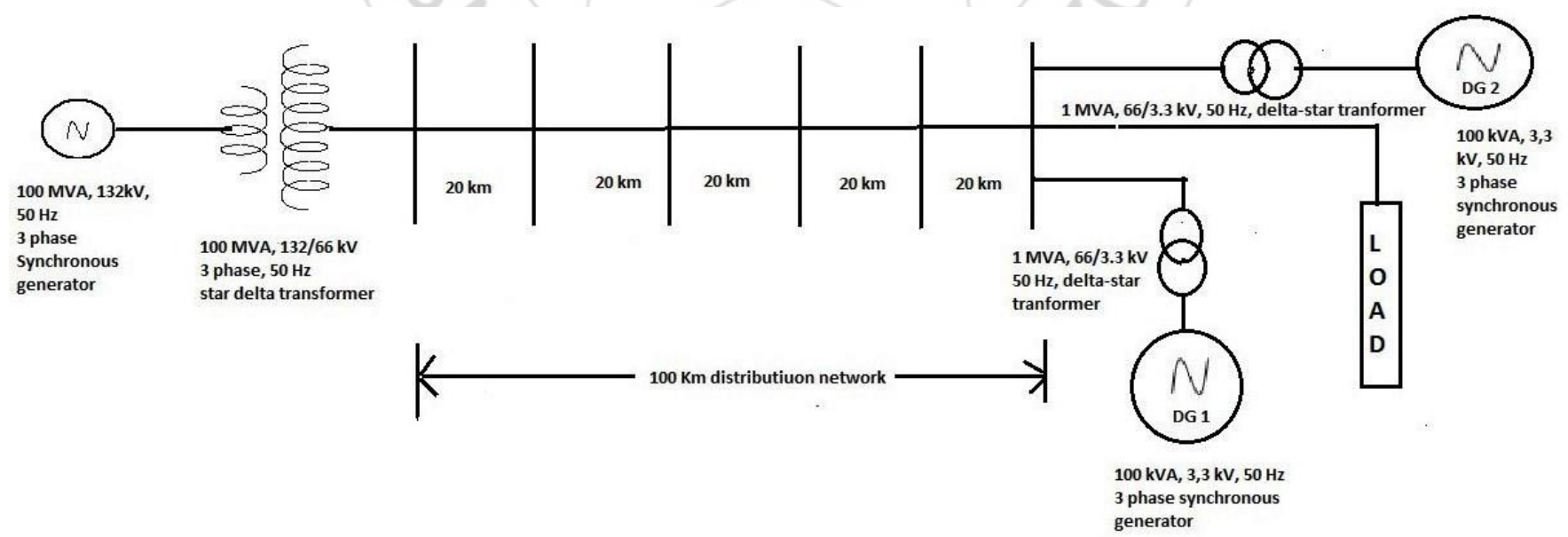

Figure 5: Single Line Diagram of a real Time system

Two distributed generations with $\mathrm{YG}$ configuration is interconnected to the grid by $\mathrm{D} / \mathrm{YG}$ distribution transformers. The grid rating is $132 \mathrm{kV} / 50 \mathrm{~Hz}$ with 3 phase short circuit level 100MVA and X/R ratio equal to 7 . The voltage is then stepped down through a two winding transformer with rating 100 MVA 132/66 kV. For measurement purpose a V-I measurement tool box is connected to this transformer as shown in figure 6. The two distributed generator each of 100 $\mathrm{kVA}$ operated at $3.3 \mathrm{kV}$ are connected to the grid through a distribution network of $100 \mathrm{Km}$ in length which is divided into 5 zones of $20 \mathrm{Km}$ each. 


\section{International Journal of Science and Research (IJSR) \\ ISSN (Online): 2319-7064}

Index Copernicus Value (2013): 6.14 | Impact Factor (2015): 6.391

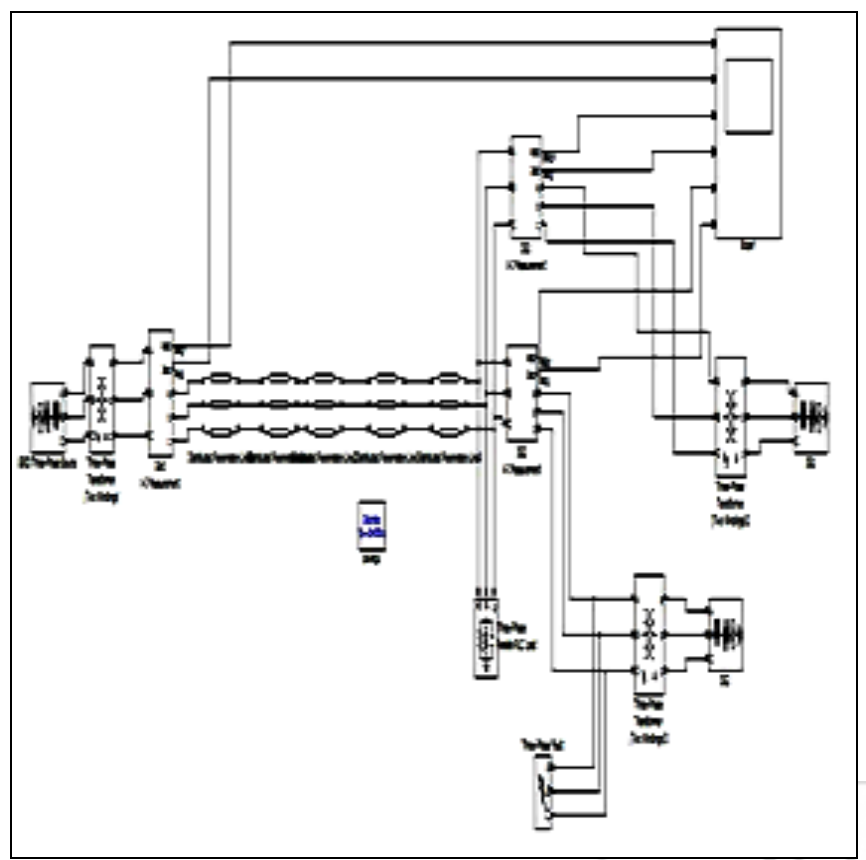

Figure 6: Real time distribution network on Simulink

For measurement purpose a common scope is connected to both Distributed generator and the grid. The measurement will be in the form of three phase voltage and three phase current of both DG's and the grid. Entire modelling of the system has been done on MATLAB Simulink. A three phase parallel load is connected at the end with rating $10 \mathrm{~kW}$. The best method for obtaining input data which involves training data for neural network data has to be from a real network in many faulty cases at different points of the network. But it is not a practically possible in a real network. Therefore, modelling of the system is mandatory for providing input patterns. For this aim MATLAB Simulink has been used for the modelling of the system and MATLAB software for defining a protection procedure and executing neural network based fault locator [10].

\section{Offline Calculation}

After modelling the system, load flow and short circuit test is being carried out at different point with grid as the reference point. There are various methods and algorithm given by so many researchers for carrying out load flow and short circuit analysis [11-20]. For simulation of the network, fault level data of points, which are $20 \mathrm{~km}$ far from each other are used. For example, for each type of fault in this case of connection of Gen 1 and Gen2, we have total of 8 locations where this fault analysis can be carried out ( 5 with in the distribution network and one near grid and two at each grid). Current vectors are chosen as randomly for the testing of system too.

Here the load flow and short circuit analysis has been carried out on the Simulink itself using 3 phase fault box. Initially to carry out load flow and steady state values of current and voltage of DG1, DG2 and grid in 3 phase fault box all are deselected.

With a simulation time of 0.2 second and sample time of 0.00002 one thousand values of voltage and current for all the three phases for grid DG1 and DG2 comes out as result. By clicking on the scope one can analyses the instantaneous value of voltage and current for all the three phases for grid DG1 and DG2.One can easily analyses from the scope that under steady state condition all the three phases current and voltages are sinusoidal and is displace from each other by 120 degrees as shown in fig 7 .

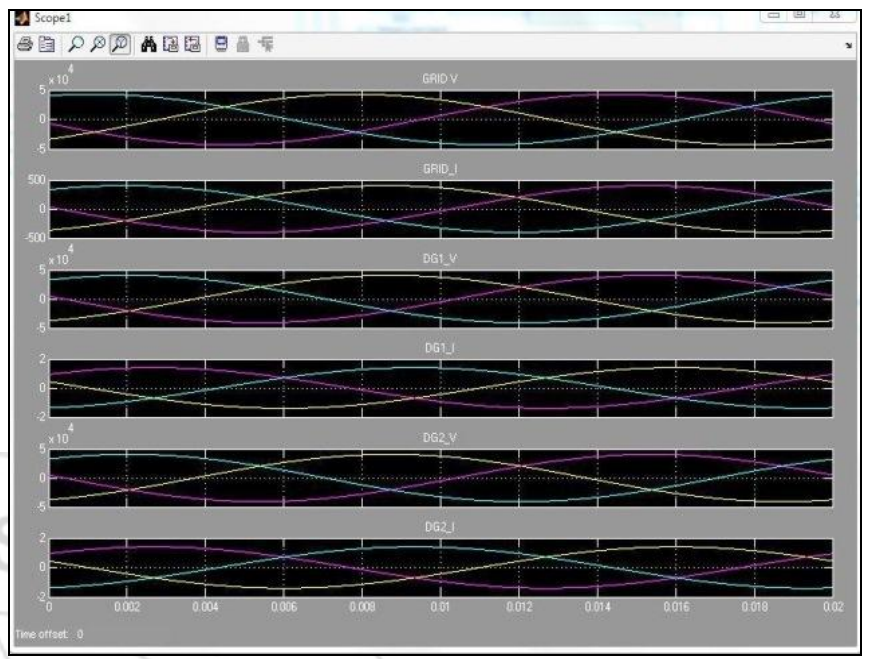

Figure 7: Scope result for balance steady state analysis

The corresponding values of voltage and current all the three phases for Grid, DG1 and DG2 can be taken from scope data which has been saved automatically. Similarly short circuit analysis can be done at this location using the same procedure and data can be collected from the scopedatal stored in workspace.

The scope result corresponding to Line to Ground fault can be checked through Scope result as depicted in fig. 8 .

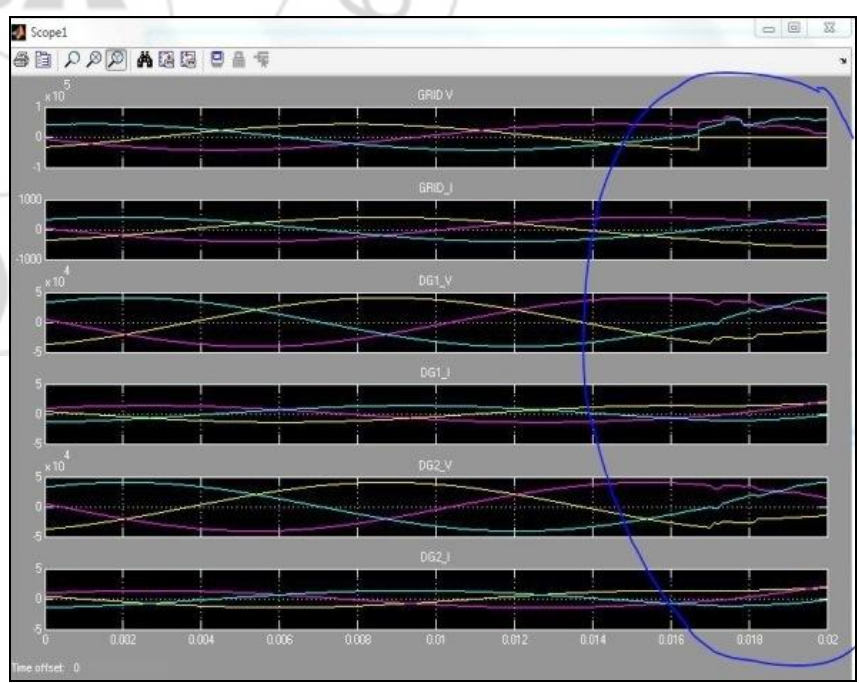

Figure 8: Scope results for A-G fault

Similarly this short circuit test can be performed at $20 \mathrm{~km}, 40$ $\mathrm{km}, 60 \mathrm{~km}, 80 \mathrm{~km}$, near load, At DG1 \& at DG2 and values of three phase voltage and current for Grid, DG1 and DG2 can be recorded via same procedure on the excel sheet as shown in Figure 9 which shows the input matrix for training of the neural network. 


\section{International Journal of Science and Research (IJSR) \\ ISSN (Online): 2319-7064}

Index Copernicus Value (2013): 6.14 $\mid$ Impact Factor (2015): 6.391

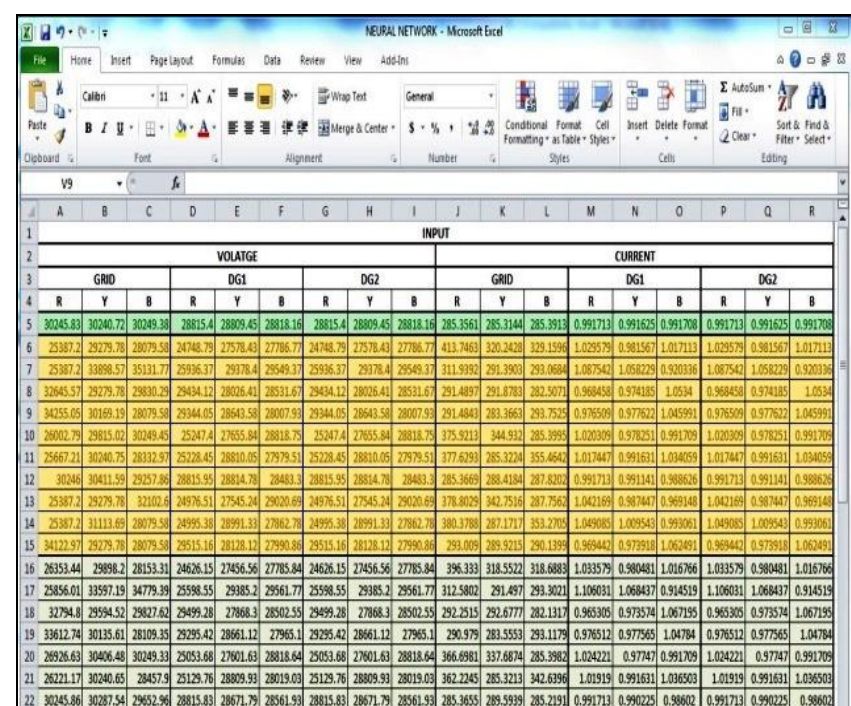

Figure 9: Input matrix showing voltage and current

For training neural network the no. of input values should not be too large and should not be too small as it will affect the neurons structure. But the recorded values are very large. So to reduce these numbers the modelling can be done so as to get RMS values of the voltage and current. This can be achieved by using an RMS block before the scope for each voltage and current of grid, DG1 and DG2.

The corresponding output coding for the recorded input matrix for Neural Network training is shown in Fig. 9 and Fig 10 respectively. These matrixes can be directly fed into nprtool as input and output or first can be converted into a text file using only values.

\section{Application of Neural Network for Data Classification}

After collecting data the major step in this process is to perform online calculation which will be done by neural network. It includes training of the neural network and based on the training validation and testing of the data by neural network.

\subsection{Artificial Neural Network}

An Artificial Neural Network (ANN) can be considered as an information refining paradigm that is encouraged by the biological nervous systems works, like brain [21]. It includes a bulk number of highly interconnected processing elements (neurons) which works in alliance for solving specific problems. ANN is defined for a particular application, such as understanding of the pattern classification of data, by a learning process. Figure 10 shows the structure of an artificial neuron.

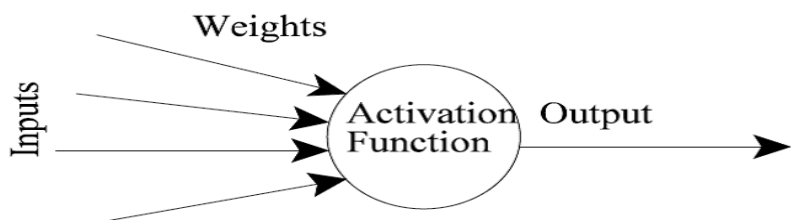

Figure 10: An artificial neuron [22]
Learning in organic systems comprises modifications to the synaptic networks that exist between the neurons [21]. These essentially contain inputs (like synapses), which are multiplied by weights strength of the corresponding signals, and then calculated by a mathematical function that governs the activation of the neuron. Another function (which may be the identity) calculates the yield of the artificial neuron (sometimes in dependence of a certain threshold). Figure 11 shows Simple neural network diagram.

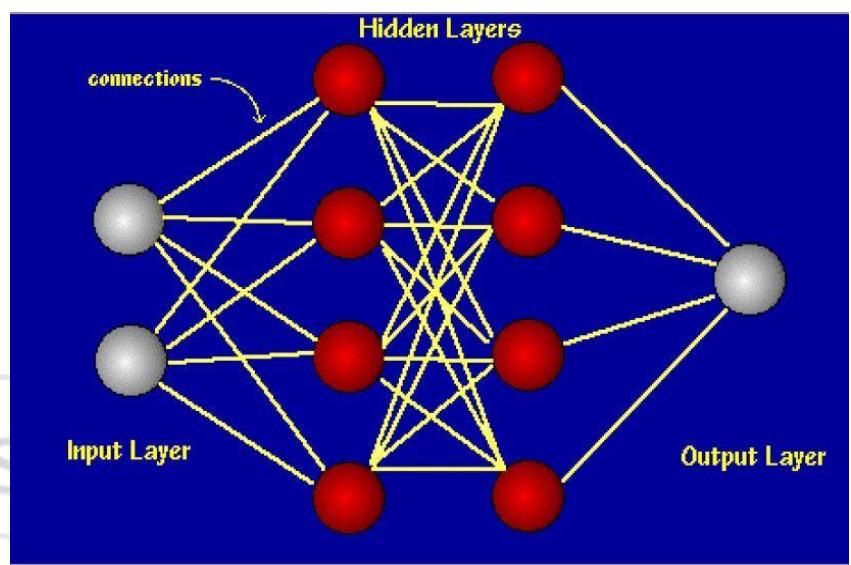

Figure 11: Simple neural network diagram [22]

The activation function used in this algorithm is nothing but a weighted sum (the summation of inputs $\mathrm{X}$ when multiplied by their respective weights $\mathrm{Wji}$ gives this weighted sum) represented by equation 2 :

$$
A_{j}(\bar{x}, \bar{w})=\sum_{i=0}^{n} x_{i} w_{j i}
$$

The most common output function used for this is a sigmoidal function which is given by equation 3 .

$$
O_{j}(\bar{x}, \bar{w})=\frac{1}{1+e^{A_{\mathrm{j}(\bar{x}, \bar{w})}}}
$$

The algorithm used for this purpose is Back-Propagation Algorithm. The network accepts inputs through neurons in the input layer; likewise the output of the network is depicted by the neurons in the output layer. There may be one or more intermediate hidden layers. Since this algorithm makes use of supervised learning, thus it provides the samples of the inputs and outputs that is needed to be computed [22].

\section{Online Calculation}

After performing short circuit test and offline calculation which comprises of collecting data regarding various faults at different locations in terms of voltage and current the next step is to perform online calculation.

Online calculation include the following step-

1)Training of neural network based on the collected data

2) Validation and testing of the data

3) Based on the testing of the data identify the fault type and its location

4)Disconnect the faulty part from the healthy system using circuit breaker and relay mechanism. 


\section{International Journal of Science and Research (IJSR) \\ ISSN (Online): 2319-7064}

Index Copernicus Value (2013): 6.14 | Impact Factor (2015): 6.391

\subsection{Training of Neural network}

To train neural network we need to have input matrix in a proper sequence which should include all the possible outcomes in terms of RMS values of current and voltage for different location and all types of fault. For identifying the types of fault the coding shown in Table 1 is being followed.

Table 1: Fault Type Coding

\begin{tabular}{|c|c|c|c|c|}
\hline \multirow{2}{*}{ Type of Fault } & \multicolumn{5}{|c|}{ Code } \\
\cline { 2 - 5 } & A & B & C & G \\
\hline No Fault & 0 & 0 & 0 & 0 \\
\hline 3 Phase Fault & 1 & 1 & 1 & 0 \\
\hline A To G & 1 & 0 & 0 & 1 \\
\hline B To G & 0 & 1 & 0 & 1 \\
\hline C To G & 0 & 0 & 1 & 1 \\
\hline AB (Line To Line) & 1 & 1 & 0 & 0 \\
\hline AC (Line To Line) & 1 & 0 & 1 & 0 \\
\hline BC (Line To Line) & 0 & 1 & 1 & 0 \\
\hline AB To G & 1 & 1 & 0 & 1 \\
\hline AC To G & 1 & 0 & 1 & 1 \\
\hline BC To G & 0 & 1 & 1 & 1 \\
\hline
\end{tabular}

Similarly for identifying the location of the fault coding as shown in table 2 has been done. This way the total no of input will be 18 and total no of output will be 12 .

In simple words it can be said that 'matrix input' is a $81 \times 18$ matrix, representing 18 samples of 81 elements and Target matrix is a $81 \times 12$ matrix, representing 12 samples of 81 elements.

Table 2: Location coding scheme

\begin{tabular}{|c|c|c|c|c|c|c|c|c|c|}
\hline \multirow{2}{*}{$\begin{array}{c}\text { Location of } \\
\text { fault }\end{array}$} & \multicolumn{7}{|c|}{ CODE } \\
\cline { 2 - 10 } & Grid & $20 \mathrm{~km}$ & $40 \mathrm{~km}$ & $60 \mathrm{~km}$ & $80 \mathrm{~km}$ & Load & DG1 & DG2 \\
\hline No fault & 0 & 0 & 0 & 0 & 0 & 0 & 0 & 0 \\
\hline Near grid & 1 & 0 & 0 & 0 & 0 & 0 & 0 & 0 \\
\hline At $20 \mathrm{~km}$ & 0 & 1 & 0 & 0 & 0 & 0 & 0 & 0 \\
\hline At $40 \mathrm{~km}$ & 0 & 0 & 1 & 0 & 0 & 0 & 0 & 0 \\
\hline At $60 \mathrm{~km}$ & 0 & 0 & 0 & 1 & 0 & 0 & 0 & 0 \\
\hline At $80 \mathrm{~km}$ & 0 & 0 & 0 & 0 & 1 & 0 & 0 & 0 \\
\hline Near load & 0 & 0 & 0 & 0 & 0 & 1 & 0 & 0 \\
\hline At DG1 & 0 & 0 & 0 & 0 & 0 & 0 & 1 & 0 \\
\hline At DG2 & 0 & 0 & 0 & 0 & 0 & 0 & 0 & 1 \\
\hline
\end{tabular}

The toolbox itself divides the data into three samples which are training, validation and testing respectively. For training purposes some samples of the data recorded earlier is presented to the network is adjusted according to its error. By default it has taken $70 \%$ (57 samples) for this purpose.

Around $15 \%$ (12 samples) are used to measure network generalization, and to halt training when generalization stops improving.

These have no effect on training and so provide an independent measure of network performance during and after training. By default it has taken 15\% (12 samples) for this purpose. This allocated percentage of the recorded data can be changed as per the requirement.

\section{Test Results}

For the test system considered which includes two distributed generators interconnected to a utility grid through a $100 \mathrm{KM}$ long distribution network, the output which comes after the training of the neural network can be directly analyzed from the snapshot shown in figure 12.

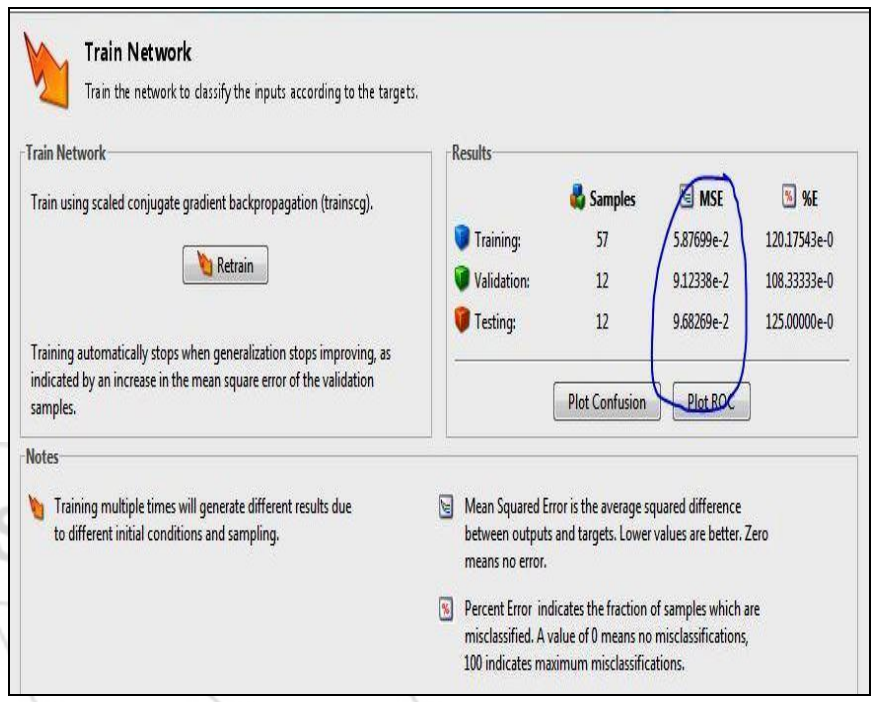

Figure 12: Training result showing MSE

Since the mean square error which is the main parameter for the successful training comes out to be very low which indicates that training and validation of the network has been completed successfully. In this case the mean square error for all the three steps training, validation and testing comes out to be very low. The performance plot indicating MEAN square error against different epoch for all the three steps i.e. training, validation and testing is shown in figure 13 .

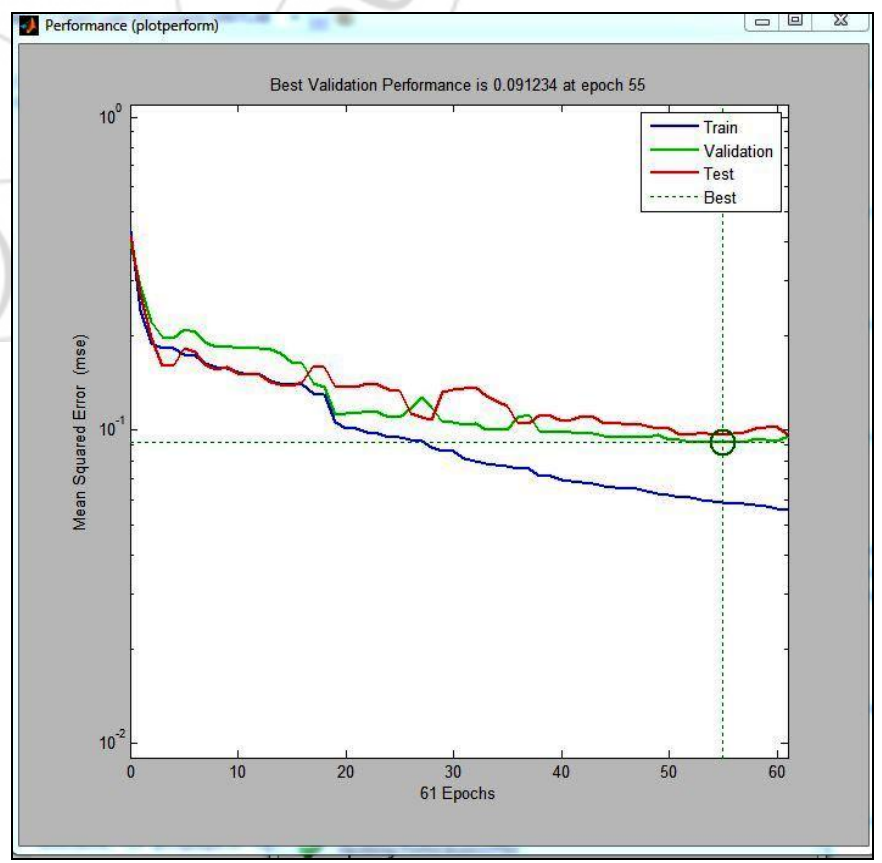

Figure 13: Performance plot

The best validation Comes at 0.091234 at 55 epoch. Similarly the confusion matrix, receiver operator 


\section{International Journal of Science and Research (IJSR) \\ ISSN (Online): 2319-7064}

Index Copernicus Value (2013): 6.14 | Impact Factor (2015): 6.391

characteristic and training state for case are shown in Fig 14 and 15 respectively.

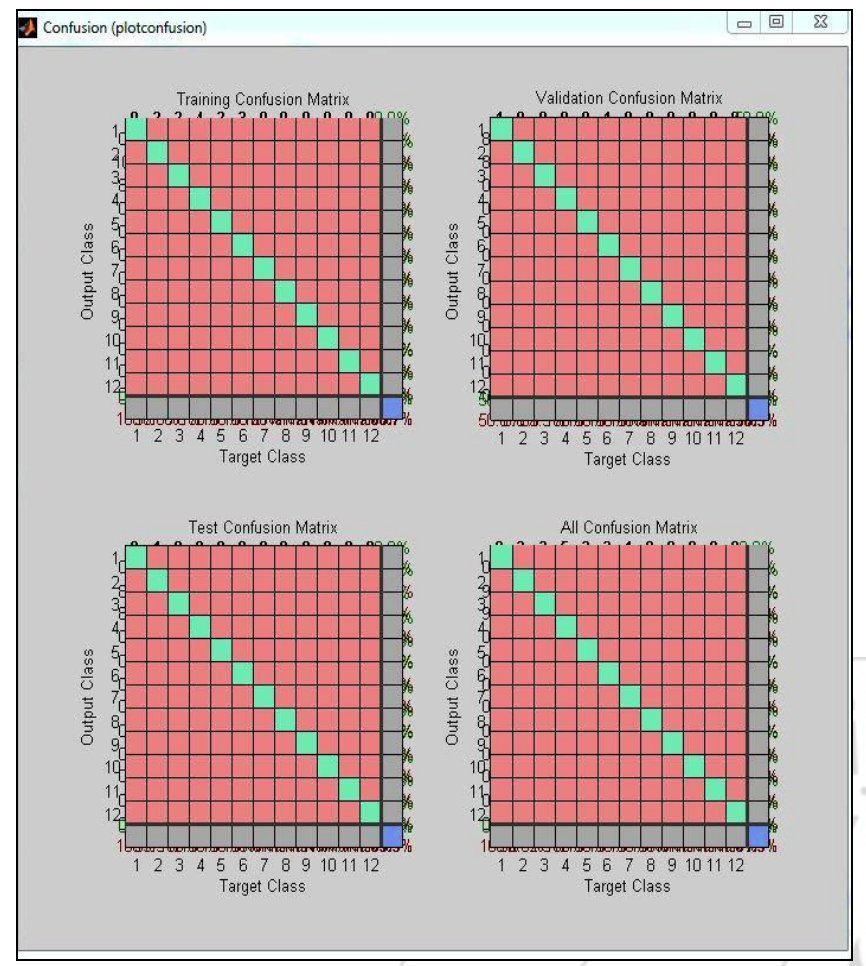

Figure 14: Confusion matrix

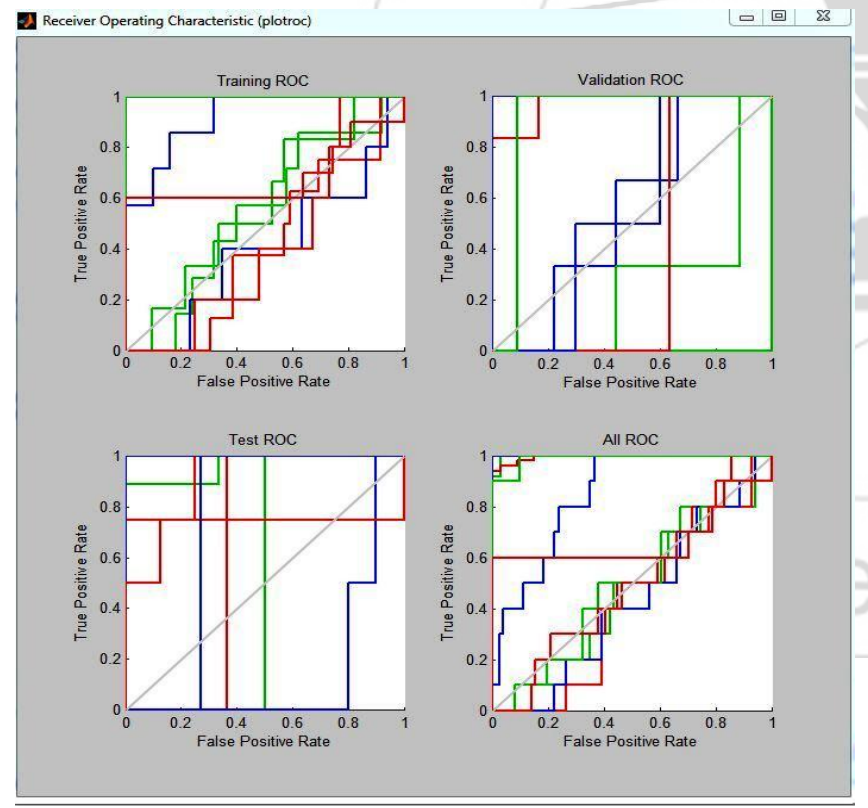

Figure 15: Receiver operator characteristics

The training state during training of the Neural Network is shown in Fig. 16.

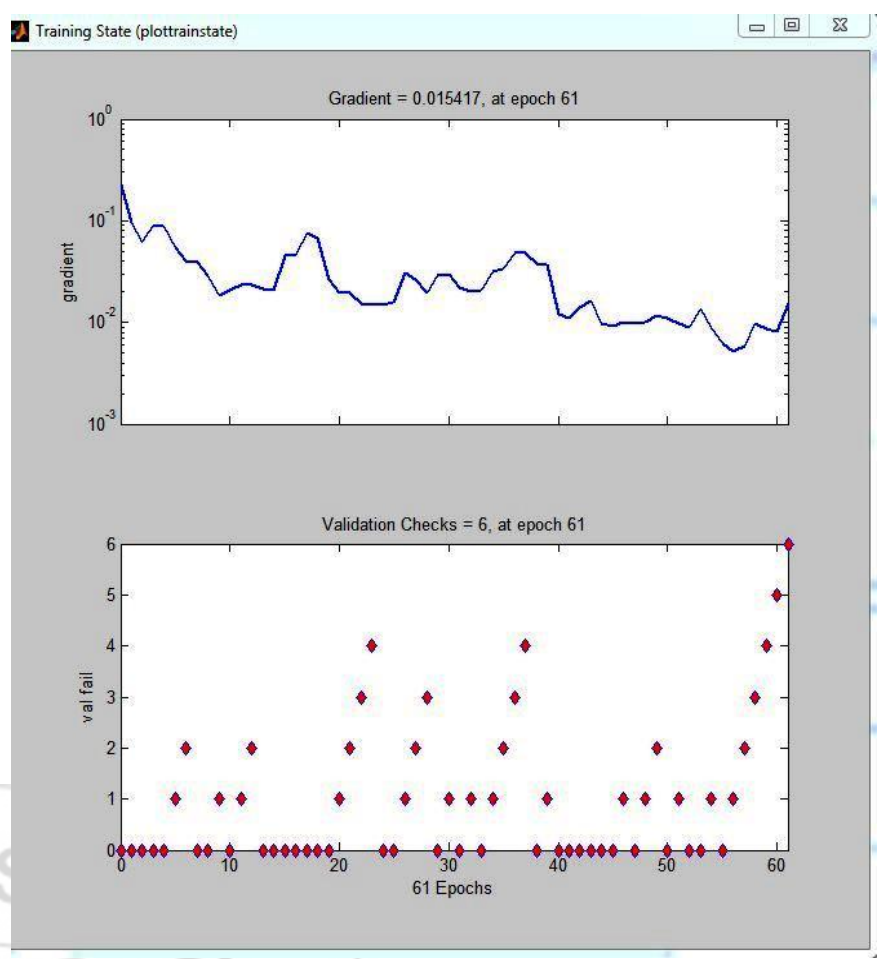

Figure 16: Training state

\section{Conclusion}

The system so considered here has been first modelled on MATLAB Simulink and then Steady state and short Circuit test have been carried out for the same with a simulation time of 0.2 second and sample time of 0.00002 . The data so collected is formulated to form Input matrix of size $81 \times 18$. Similarly the output matrix can be made with 12 output and $12 * 81$ elements. The same has been fed to a neural network with 20 Neurons in the hidden layer and 12 in the output layer.

Out of the 81 samples 57 have been used for training and 12 each have been used for Validation and testing Purpose. The results have been expressed in terms of MSE (Mean Square Error) which was coming out to be very close to Zero. Also the performance plot which is a direct indication of the successful training, testing and Validation shows that Best validation occurs at 55 epoch.

After successful training, testing and validation the trained Neural Network in the event of any fault identifies its type and location on account of the pattern recorded. However the Mean square error shows that there are still some variances between the actual result and expected result which can be improved by using some other algorithm other than back propagation. Also this method can be further applied to a larger network and can be linked with the conventional protection scheme to improve the reliability of the system.

\section{References}

[1] http://dspace.vpmthane.org:8080/jspui/bitstream/12345 $6789 / 1383 / 2 /$ Renewable\%20Energy.pdf $<$ accessed on 15 September, 2015> 


\section{International Journal of Science and Research (IJSR) \\ ISSN (Online): 2319-7064}

Index Copernicus Value (2013): 6.14 | Impact Factor (2015): 6.391

[2] Martin, Jeremi. "Distributed vs. centralized electricity generation: are we witnessing a change of paradigm." An introduction to distributed generation. Paris: HEC : $<$ www. vernimmen. net/ftp/An_introduction_to_distributed_generation.pdf ( 2009). $<$ accessed on $17^{\text {th }}$ September, 2013>

[3] P. Chiradeja and R. Ramakumar "An approach to quantify the technical benefits of distributed generation " IEEE Transactions on Energy Conversion, volume 19, issue 4: pp. 764-773, (2004)

[4] Bastiao, Fernando, Paulo Cruz, and RuiFiteiro "Impact of distributed generation on distribution networks" In Electricity Market, 2008.EEM 2008. 5th International Conference on European, pp. 1-6. IEEE, 2008 Fujisawa.

[5] Philip P. Barker and W. De Mello. Robert "Determining the impact of distributed generation on power systems I Radial distribution systems" In Power Engineering Society Summer Meeting, 2000. IEEE, vol. 3, pp. 16451656. IEEE, 2000.

[6] Roger C. Dugan, and Thomas E. McDermott. "Operating conflicts for distributed generation on distribution systems." in rural Electric Power Conference, 2001, pp. A3-1. IEEE, 2001.

[7] Brahma, Sukumar M., and Adly A. Girgis"Development of adaptive protection scheme for distribution systems with high penetration of distributed generation"Power Delivery, IEEE Transactions on 19, no. 1 (2004): pp. 56-63.

[8] N. Rezaei and M-R. Haghifam "Protection scheme for a distribution system with distributed generation using neural networks" International Journal of Electrical Power \& Energy Systems 30, no. 4: pp. 235-241, (2008)

[9] Nicholas Jenkins, "Embedded generation." Power engineering journal 9, no. 3: pp. 145-150, (1995).

[10] Electrical Transient Analyzer Program Manual, part 2, short circuit study. Operation Technology, Inc., Certification no. A3147; 2002

[11] Marián Mešter, "Calculation of the fault level contribution of distributed generation to distribution network."

[12] Carol S. Cheng and Dariush Shirmohammadi, "A threephase power flow method for real-time distribution system analysis, "IEEE Transactions on Power Systems, volume 10, issue 2: pp. 671-679, (1995)

[13] Dalia N. Hussein, M. El-Syed and H. A. Attia. "Modeling and simulation of distributed generation (DG) for distribution systems load flow analysis." Power Systems Conference, 2006. MEPCON 2006. Eleventh International Middle East. Vol. 1. IEEE, 2006.

[14] R. Anish and D. P. Kothari. "Modeling and analysis of grid networks with Distributed Resources using MATLAB/SIMULINK." IEEE International Conference on Power Electronics, Drives and Energy Systems (PEDES), IEEE, 2012.

[15] Hongbo Sun, "A fast and robust load flow method for distribution systems with distributed generations." Energy Procedia 12: pp. 236-244. (2011).
[16] Luis A. Gallego, Carreno Edgar and Padilha-Feltrin Antonio, "Distributed generation modelling for unbalanced three-phase power flow calculations in smart grids." Transmission and Distribution Conference and Exposition: Latin America (T\&D-LA), 2010 IEEE/PES. IEEE, 2010.

[17] J. Olamaei , A. Ghasemabadi Mojtaba and Mohammad Heidari Kapourchali. "An efficient method for load flow analysis of distribution networks including PV nodes." 2nd International Conference on Electric Power and Energy Conversion Systems (EPECS), 2011, IEEE, 2011.

[18] Jen-Hao Teng, "Unsymmetrical short-circuit fault analysis for weakly meshed distribution systems." IEEE Transactions on Power Systems, 25.1: pp. 96105, (2010).

[19] D. Das, H. S. Nagi, and D. P. Kothari. "Novel method for solving radial distribution networks." IEE Proceedings-Generation, Transmission and Distribution 141.4: pp. 291-298, (1994).

[20] S. Ghosh and D. Das. "Method for load-flow solution of radial distribution networks." IEE ProceedingsGeneration, Transmission and Distribution 146.6 (1999):pp. 641-648, (1999)

[21] Carlos Gershenson, "Artificial neural networks for beginners." arXiv preprint cs/0308031 (2003).

[22] Jianchang Mao and Anil K. Jain. "Artificial neural networks for feature extraction and multivariate data projection."IEEE Transactions on Neural Networks, volme 6, issue 2 :pp. 296-317, (1995).

\section{Author Profile}

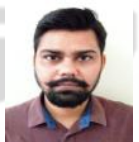

Saurabh Awasthi received the B.tech degrees in Electrical Engineering from Bundelkhand institute of engineering \& Technology, Jhansi, India in 2011. Later he had completed M. tech in Alternate Hydro Energy Centre from IIT Roorkee, India in 2014.. He is presently working as Assistant Professor in DIT University, Dehradun.

Ranjay Singh received the B.tech degrees in Electrical Engineering from UIET, Panjab university, Chandigarh, India in 2011. Later he had completed M. tech in Power Electronics from MNNIT, Allahabad, India in 2014.. He is presently working as Assistant Professor in DIT University, Dehradun. 